\section{AN EXHIBITION OF FRUITS AND VEGETABLES IN WAX.}

A sclentific classification of fruits and vegetables finds attractive illustration in a series of exhibits of waxen products in the museum department of Carnegie Institute, Pittsburg, $\mathrm{Pa}$., as prepared and arranged by the section of botany of the Institute. The idea of the portrayal of familiar edible growths

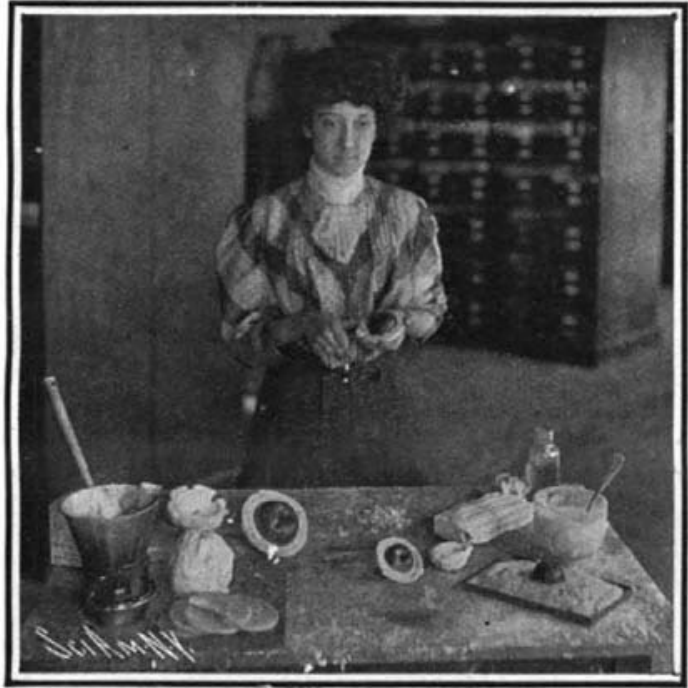

Removing the Fruit from the Plaster Mold.

in wax as a museum feature of study is a new one, although one or two agricultural colleges have made small beginnings in this line, and also the Department of Agriculture at Washington has at present under consideration an elaboration of the same method of exhibition and comparison.

The exhibit in Pittsburg includes the fruits proper, such as the apple, peach, pear, plum, and the like; the products known as vegetables; nuts of all kinds; grain crops with the various cereal products and byproducts; root crops, plants used in medicine; fiber plants utilized in cordage and textiles; plants cultivated for the edible stems and leaves, such as spices and condiments; also a display of woods. such as dyewoods, sugars, gums, resins, and woods, sugars, gums, resins, and
lumber. The exhibit appeals to scientific and research students, in deed to all classes, including housekeepers, who are not only captivated by the realistic qualities of the artificial products; but instructed as to the manner of growth of certain fruits and the section of country from which many familiar edibles are derived.

The most popular phase of the exhibit, of course, is the method of showing the edible fruits. It is a difficult thing, for instance, to indefinitely preserve perishable fruits in such a manner that they may be used for display purposes in a museum showcase and still retain their natural colors. The usual method is to place the fruits in a weak solution of formaldehyde, alcohol, sulfurous acid, or zinc chloride. But when this is done, the products are distorted by the glass jar filled with liquid and in time the colors fade. The Carnegie Museum through its capable director seum through its capable director,
Dr. William J. Holland, when the Dr. William J. Holland, when the
exhibit of edible products was decided upon, determined to duplicate the natural fruits in wax, and by tinting with permanent paints to reproduce as closely as possible the appearance and color of the real products. A workroom was set aside for the modeling and painting of the fruits with Mr. Otto Emery Jennings, head of the section of botany, in charge. Mr. Jennings was given full authority to make purchase of the natural products wherever they might be found, the world over, and privileged to originate and develop special plans of his own as to the details of the manufacture and display of the artificial duplicates, with Mrs. Jennings as his enthusiastic assistant, he has not only succeeded in laying the foundation for a remarkable exhibit in time of every known specimen of edible growth in the whole vegetable kingdom as illus trative of economic botany, but has

already placed on public view an arrangement of products both instructive and picturesque.

The method of manufacture of the waxen fruits in the busy workroom is most interesting. The fruit specimen is indented in sand up to one-half; the exposed half, well greased, is then treated to a heavy coating of plaster of Paris; when this coating dries, the specimen is reversed and the coated half, plaster and all, is thrust into the sand, and the exposed portion of the fruit is greased and coated as at first. When dry the plaster molds are separated and the fruit is gently pried out. The half molds are then tied together, a small opening is made, then a refined beeswax, melted, is poured into the opening and the molds are set aside until the wax hardens. One of the illustrations shows Mrs. Jennings at the modeling table in the act of removing a real fruit specimen from the mold.

The waxen fruits when hardened are painted by the artist, who keeps the real specimen constantly in view, and strives not for mere artistic beauty, but for an exact reproduction of the natural tints and markings. Casts are also made of fruits cut in sections, and the wax is faithfully tinted to show the seeds, the core, the interior color, texture, and the relation of the size and position of the various parts In one illustration may be seen the fruits whole and in sections on the drying rack after the tinting, and in another is shown the artist at the painting task.

In the fruit specimens already on display are the leading apples of the North, the Baldwin, the Rambo, the Russet, the Greening, and the like down to the pretty little Lady apple, the fancy visitant of the winter in its satiny skin of yellow and crimson; there are the pears with the handsome winter Bartlett in the lead; the peaches, from the common downy variety to the smooth-skinned nectarine; the bananas in the familiar yellow and the plump short Jamaica in its deep, purplish red skin; the pomegranate in its rough orange-like covering; the avocado, the pearshaped fruit from four to five inches long with skin beautifully mottled in purple and green; then in pleasing array the pineapple, the clusters of grapes, the cherries, the plums, the apricots, the persimmons, the berries, the strawberry, the gooseberry, blackberry, raspberry, currants, and small fruits. Then the citrus fruits, which to many are the most interesting of all

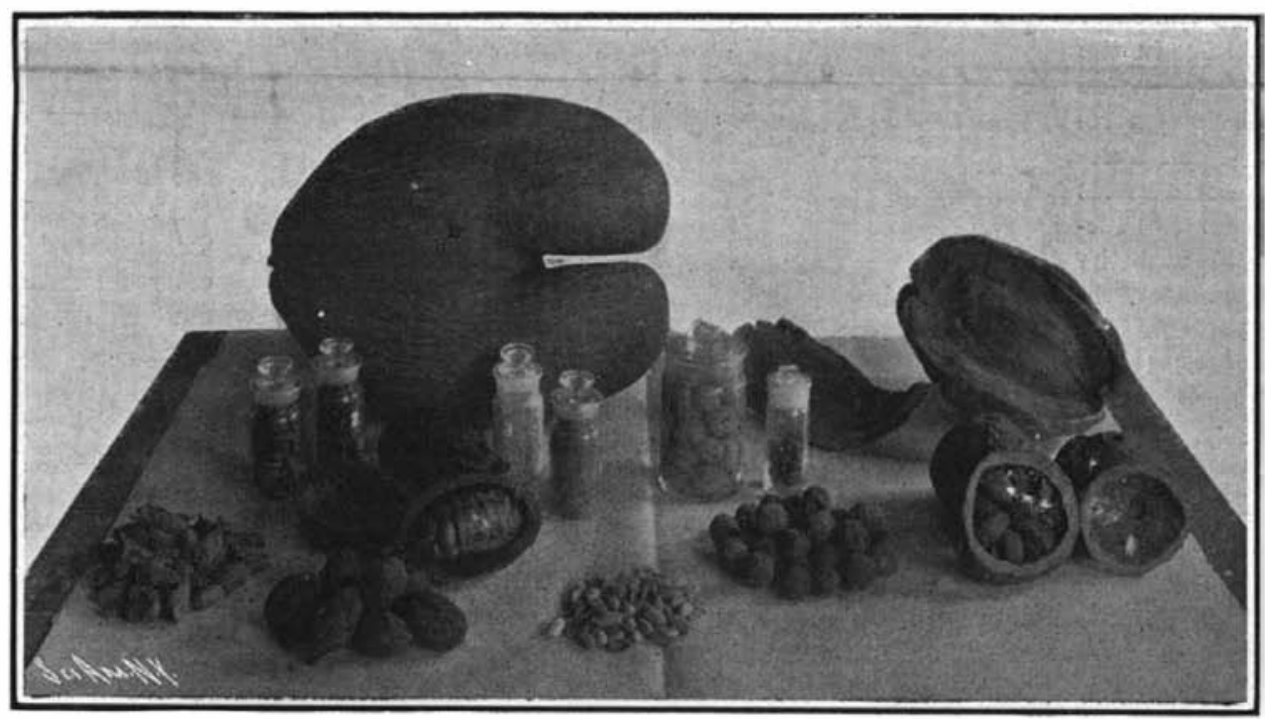

A Nut Group With By-Products.

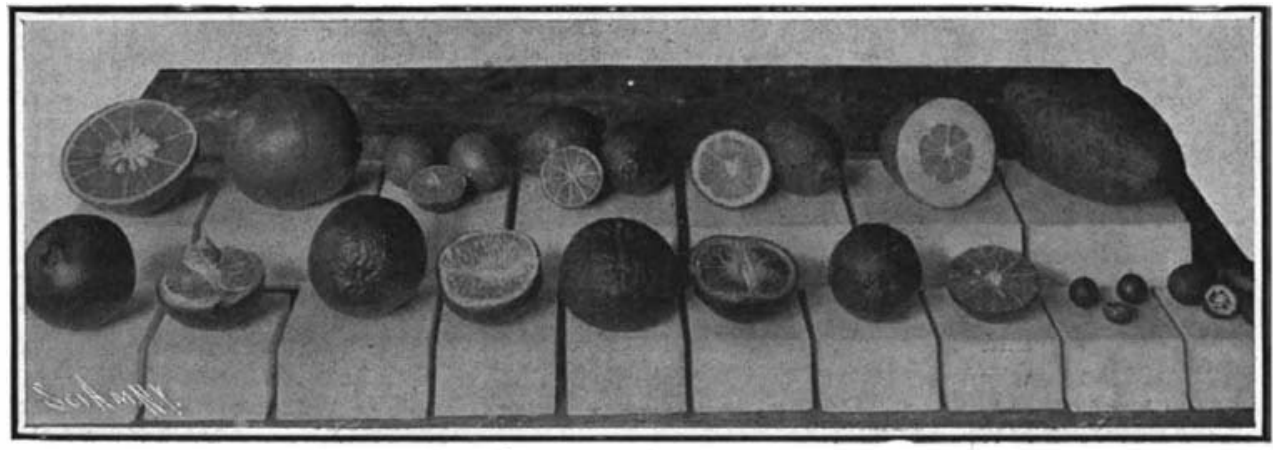

The Citrus Group in Wax.

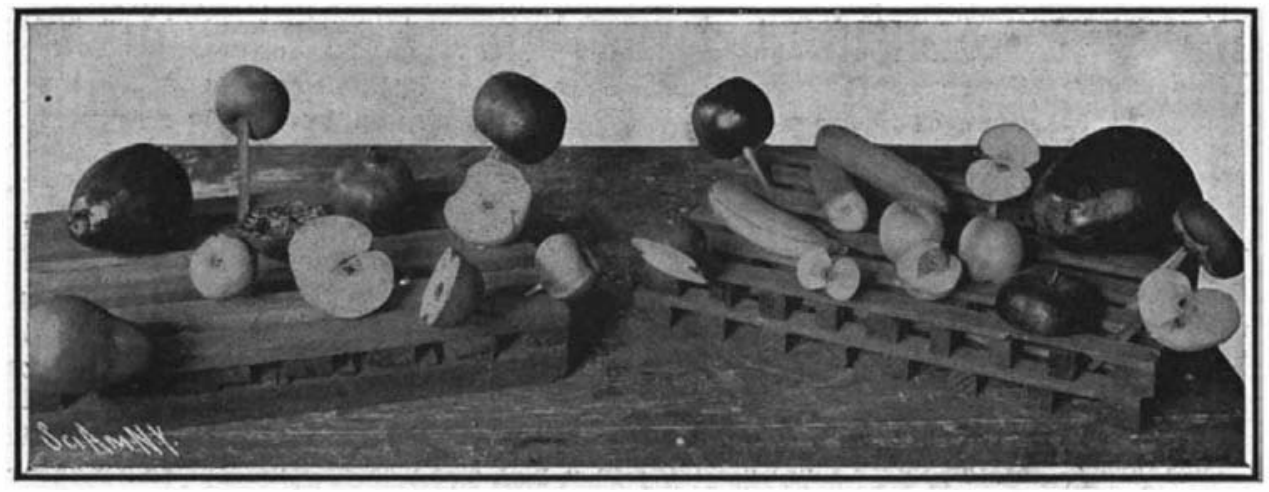

Models on the Drying Rack After Painting.

AN EXHIBITION OF FRUITS AND VEGETABLES, on account of their beauty and variety. There is the large citron from Italy, seven inches long, in color and shape resembling an immense lemon and the "peel" of which in the natural product is nearly an inch thick and is used for candied citron and preserves; there is the Florida rough lemon, a hybrid between the citron and the true lemon and often sold in the market for the latter; then the real lemon and the lime, the latter a small round fruit resembling the

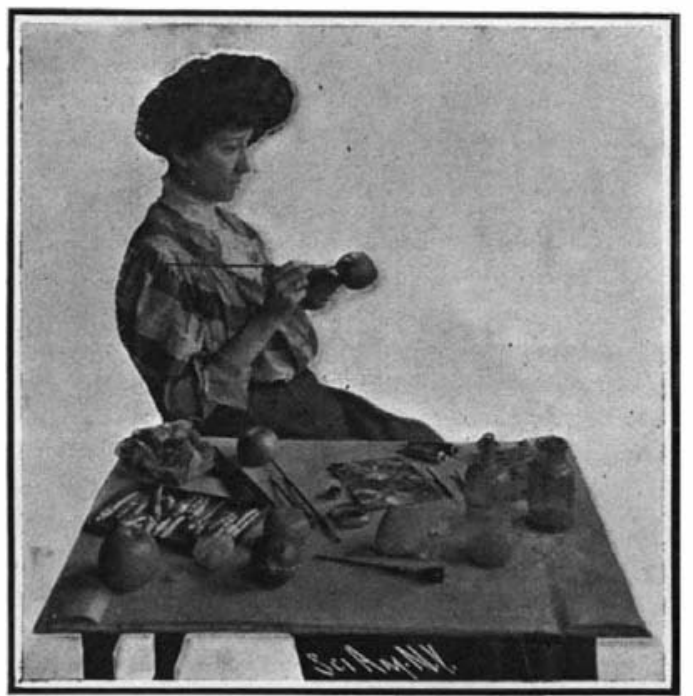

Painting a Waxen Cast.

lemon in color, but in nature with a very thin skin and an intensely acid pulp. The grapefruit belongs to this citrus group. This fruit, which takes its name from the habit of some varieties of hanging in grapelike clusters, is shown both in the light yellow-colored pomelo, which is popular as dessert, and in the long pear-shaped forms called shaddocks, a product of the old world. Oranges, which come in the citrus group, are shown in all forms from the King mandarin with its thick russet skin, and the tangerine, a smaller mandarin, through the common or sweet varieties, and the navel orange, to the little kumquats, which are sold in the markets in quart crates like strawberries. The illustration shows a completed citrus group.

The nut group is an interesting one. There are the cocoanut, the English or Persian walnut, the almond, the wild and cultivated chestnuts, the wild and cultivated hazelnuts, the pecans, the black walnut, the white walnut, butternuts, hickory nuts, and on through the list.

In the illustration is seen the cream nut or Brazil nut in the original shell. The so-called nuts are packed together, twenty-five or fifty of them, in a hard bony shell resembling that of the cocoanut. Around the whole is an outer growth, or shell, similar to that of the black walnut. The pistachio nuts are the small nuts seen in the center of the picture. These nuts are much used in confectionery, and, in Europe, for flavoring meats. The nut is about the size of the meat of the peanut, and is inclosed in a thin hard shell of a light yellow color. The Lychi nut is a Chinese favorite. It is shown directly in front of the two vials of its byproducts, namely, preserves and dried fruit. The meats of the nut are canned by the Chinese much as the Americans can peaches. The meat in the raw state has the resemblance and flavor of a raisin. The cocoanut is seen in the picture, also a group of butternuts and filberts. The immense nut in the background is a coco-de-mer, or "a cocoanut which floats on the sea," after tumbling from the trees along the shore. It is captured by natives along the shores of the islands in the south of the East Indies. The meat of the great nut is used for medicines, the shell for the fashioning of utensils, and the outer covering for the thatching of the native huts. In front of this great nut in the picture is shown the cocoa-pod, the fruit of the cacao tree, and not of the cocoanut palm. This is interesting to housekeepers from the fact that it is the shell of this nut which is so frequently ground up and sold as spices in the market on 
account of its spicy taste. The shell is from a quarter to half an inch in thickness, and incloses forty or fifty oblong seeds about the size of a lima bean. These seeds broken into small pieces are called cocoa nibs, and from these is obtained cocoa butter. The nibs after this use are then ground into the cocoa which is used as a beverage. When the nibs are ground up without the extraction of the butter, the product therefrom constitutes the common household chocolate. The vials in the picture contain the by-products, that is, seeds, nibs, butter, and cocoa, but, it is needless to say, no adulterated spices.

The exhibit also includes a long list of grains, together with the various flours, meals, and other cereal products. There is the durum, or macaroni wheat, a hard wheat much grown in Russia and Algeria and now beginning to be cultivated in our Northwest and from which the semolina or flour is made, and from this in turn the macaroni, spaghetti, and noodles. There are the fibers, also the flax.before retting, the tow or raw fiber, the cords and threads of various grades and sizes; and the cotton, raw cotton; cotton from scutching; cotton from cards; also specimens showing the various processes up to the finished yarns and fabrics. Then the fibers of the jute, the hemp, the sisal, and the "new linen plant," a Brazilian plant nearly related to cotton, are represented in all raw and partially prepared and finished states.

The medicine roots, stems, and leaves are an interesting class in themselves. There are the specimens of castor bean, the sassafras roots, the slippery elm, flaxseed, sweetflag, burdock, boneset, mustard, aloes, foxglove, golden seal, licorice, ginger, quinine, witch hazel, and on through an exhaustive and instructive list.

\section{Seux's Aeroplane.}

Among the new aeroplanes which are being tried in France is a flyer designed by M. Edmond Seux, secretary of the aviation section of the Aero Club of the Rhone. After making a theoretical study of the problem, he constructed a flyer which embodies some of the principles of a bird's flight. Curved surfaces somewhat resembling a bird's wing are used here, and to carry out this idea the front part of the curved surface is made thicker. Mr. Seux claims that this arrangement adds greatly to the stability and makes it possible to attack the air at a small angle of two or three degrees. The sides of the wings can be raised or lowered by means of springs, and the stability in the longitudinal direction is given by two rudders. In the front is a rudder which can be operated by the aeronaut at the start, but afterward it is to work automatically. The rear rudder is quite automatic in its action, and is held by a spring. The total carrying surface is 24 square meters (259 square feet) and the apparatus weighs 470 kilogrammes $(1,034$ pounds). It is equipped with a 35-horse-power motor of the Anzani pattern. As to the helices, there are two of these, mounted one on each side of the central framework. It is claimed that this disposition, which is used in the Lebaudy airship, has the advantage of working the propellers upon air which is not disturbed by tie movement of the apparatus, and it gives a better balance with an increased yield from the propellers. Following the above-mentioned principle, the propellers, which have two blades, are thickened on the front edge of the frames or the part which cuts the air. The framework is made to run upon the ground upon four wheels, and is built of steel tubes. After the preliminary trials, which proved the apparatus to be in good order, an attempt was made to fly in the air, but this was not successful owing to several difficulties which can no doubt easily be overcome. It was run at a speed of 20 miles an hour with the front part somewhat raised, but the angle was no doubt too great, which caused the flyer to tilt backward, making the propeller touch the ground and breaking it. The result showed that the rear wheels are too low and not strong enough, and that the flyer is to be directed in the air at a very small angle. But in order to do this the speed must be increased, and a heavier motor will be needed, or a lightening of the load. On the other hand, it is noticed that the stability in the lateral sense is very good, and this has been a difficult point to obtain up to the present.

\section{Weeds or Great Value.}

New Zealand flax is one of a number of wild weeds that yield their gatherers great wealth. This flax, the strongest known, grows wild in marshes. When it is cultivated it dwindles and its fibers become brittle and valueless.

Indian hemp grows wild, and out of it hasheesh, or keef, is made. Keef looks like flakes of chopped straw, It is smoked in a pipe; it is eaten on liver; it is drunk in water. It produces an intense, a delirious happiness; and among Orientals it is almost as highly Irized as beer and whisky with us.

The best nutmegs are the wild ones. They grow throughout the Malay Archipelago.
But the most valuable weed of all these wild growths is the seaweed. The nitrate beds of South America, which yield something like $\$ 65,000,000$ a year, are nothing but beds of seaweed decomposed.

\section{THE MOON'S PHASES AND ECLIPSE IN JOLY, 1907.} BY TREDFRTO $R$. HONET, TRINITY COILBOE

The moon's orbit is one of the most interesting studies in astronomy, because of the varying positions of our satellite relative to the sun and earth, and the fact that it is larger than any other satellite in our system in proportion to its primary.

Twice in every month the earth and the moon exchange places relative to the sun, whose attraction, combined with that exerted by each body upon the other, results in a modification of the form of the moon's orbit, which is an ellipse whose plane is inclined at an angle of a little over five degrees to that of the ecliptic.

This plane slowly changes its position as indicated by the line of nodes, which is its intersection with the plane of the ecliptic. The position of this line for each year for nineteen years was indicated in a recent article by the writer. (See "The Eclipse of the Sun in 1907," Scientific American for May 25).

The eccentricity of the moon's orbit is on the average a little more than one-twentieth; but it varies between wide limits, bringing our satellite sometimes thirty-one thousand miles nearer the earth than the maximum distance. It should also be noted that the moon's perigee is continually changing its position, making a complete revolution in about nine years.

The plot of the orbit (Fig. 1) must therefore be

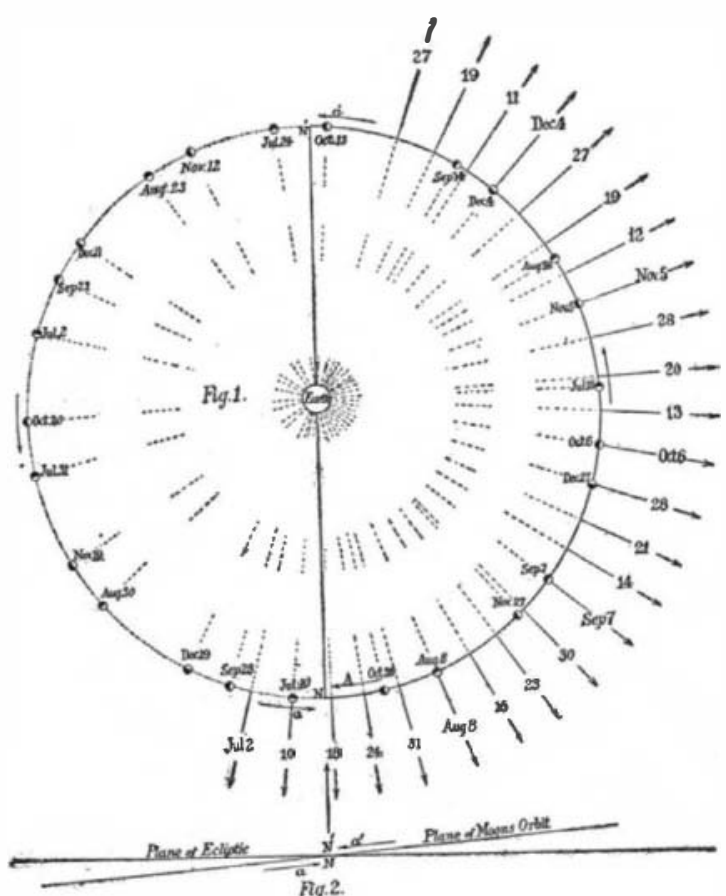

THE PLOT OF THE MOON'S ORBIT.

regarded only as an approximation, which on a small scale is sufficiently accurate for the present purpose, which is to exhibit the phases of the moon for the latter half of this year, and the conditions which will result in the eclipse of July 24 . The direction of the moon's motion is shown by the arrows marked $a$ while the arrow $A$ indicates the direction of motion of the ascending node that is opposite to that of the moon, which results each year in advancing the dates of the eclipse seasons.

In treating the eclipse of the sun in 1907 , the edge view of the plane of the ecliptic and of the moon's orbit was drawn as if seen from the earth. Fig. 2 on this page is a view from the opposite direction, an one which includes both the ascending and descendin nodes. Thus the arrow $a$ in Fig. 2 corresponds with in Fig. 1, showing the path of the moon when she is approaching the ascending node $N$ on the side neare the observer; while the arrows marked $a^{\prime}$ in Figs. the observer; while the arrows marked $a^{\prime}$ in Figs.
and 2 indicate the direction of the moon's motion when she is approaching the descending node $N^{\prime}$ on the side farthest from the observer.

Regarding the plane of the ecliptic as horizontal and in the plane of this page, that part of the moon's orbit which is above the plane of the ecliptic is represented by the full line, and that part below that plane is shown by the dotted line. The positions of the moon are shown for the dates attached, which are those of the four quarters for the last six months of this year. The dates are given in the accompanying table.

Since the distance between the sun and the earth is on the average three hundred and eighty-nine times the distance between the earth and the moon, it is impossible to include the sun and the orbit of the earth in a plot whose scale is large enough to illustrate th moon's orbit. In Fig. 1 the diameters of the earth and moon are enlarged; in order to make the phase of the latter more apparent in a plot of these dimen sions. The earth is here regarded as stationary, and the varying positions of the sun relative to the earth at the dates attached are shown by the arrows, which indicate the direction in which it is seen; 1. e., Fig. 1 shows the longitudes of the sun and of the moon at those dates.

On July 24 the moon will be at perigee. On that day she will pass the descending node $N^{\prime}$; but the sun, the earth, and the moon will not be in the same straight line. Later in the same day, when the moon will have passed below the plane of the ecliptic, the eclipse will occur. The result will be a partial eclipse visible at Washington and North America generally, xcepting the Northwest.

The following "times of the phases" are from the Nautical Almanack:
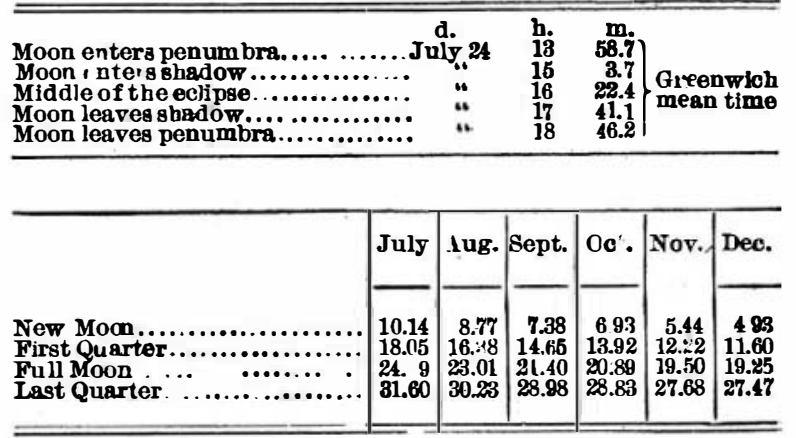

Grammar of the Indian Languages.

Prof. A. L. Kroeber, of the University of California, declares that Indian languages are not a jargon, as is popularly believed. In a pamphlet recently issued on the Yukuts and Yuki languages he affirms that Indian languages possess an elaborate and difficult grammar, though this is unknown to the Indians themselves, and must be extracted by the investigations of scientists. The two languages which Prof. Kroeber selected for experiments had absolutely no similar words. They are more different than English and Russian. The Yukuts and the Yuki are not even in territorial contact, and show no signs of common origin. The Yuki live in northern California in the Coast Range, and the Yukuts are located in the interior of south central California in the southern end of the San Joaquin Valley. Though Prof. Kroeber found that the grammatical structure of their languages was identical at nearly every point, the words were wholly dissimilar. The two languages are like houses on the same plan, but of different material.

The sentence structure employed in the two languages is full of interest. The order of words differs quite thoroughly. In Yukuts the adjective precedes the noun, in Yuki it follows. Yukuts tend to place the verb at the head of the sentence, Yuki at the end. The numerical systems of the two languages are radically different. That of Yukuts is decimal, of Yuki quaternary. It is noted by Dr. Kroeber that California has more totally distinct Indian languages per square mile than any other State. The reason for this great variety of languages has never been properly accounted for.

\section{The Fiala Trip to the North Pole.}

Capt. George Comer, of East Haddam, Conn., who is to command the Fiala expedition in search of the North Pole, sailed from New London in the 58-ton vessel "E. T. Gifford" to establish bases of supply for the main expedition, which will set out several months later. The "Gifford" will shape its course toward Cape Fullerton, Hudson Bay, and will then proceed further north.

Figures compiled at the request of E. H. Harriman show the extent to which Pacific coast shippers have been delaying the unloading of freight cars. The records of the principal California and Oregon shipping centers show that since April 1 an average of 3,632 cars per day were held overtime for unloading on the Harriman lines in this territory. From that date to May 1 conditions grew worse, but the June records show considerable improvement owing to the railroad's insistence that cars be released. Portland shippers on April 1 were holding 674 cars, which they had ncreased to 823 on May 1, and reduced to 216 by June 11. San Francisco, which had 1,860 cars tied up on April 1, was holding 2,358 May 1, and 1,640 June 12 Oakland's record was 494 for April 1, 429 for May 1, and 365 the middle of this month. Sacramento and Los Angeles shippers are holding 150 more cars now than on May 1. The average number of cars so withheld from service aggregate over twenty per cent of the total new equipment bought by the Union Pacific and Southern Pacific for delivery up to July 1. This new equipment amounts to 8,000 cars for the latter system and 7,000 for the Union Pacific lines.-Railwas and Engineering Review.

Modeling Wax.-White wax 50 parts, turpentine 15 parts, cinnabar 10 parts, glycerine 5 parts, to be melted and stirred. 